\title{
The Architecture of Financial Networks and Models of Financial Instruments According to the "Just Transition Mechanism" at the European Level
}

\author{
Otilia Manta ${ }^{1,2}{ }^{\circledR}$, Kostas Gouliamos ${ }^{3}$, Jie Kong ${ }^{4}$, Zhou Li ${ }^{5}$, Nguyen Minh Ha ${ }^{6}{ }^{3}$, \\ Rajendra Prasad Mohanty ${ }^{7}$, Hongmei Yang ${ }^{8}$, Ruihui Pu ${ }^{9}$ and Xiao-Guang Yue ${ }^{3,7,8,10, *}$ \\ 1 Romanian Academy, Center for Financial and Monetary Research “Victor Slăvescu”, 050711 Bucharest, \\ Romania; otilia.manta@icfm.ro or otilia.manta@rgic.ro \\ 2 Research Department, Romanian-American University, 012101 Bucharest, Romania \\ 3 Department of Management and Marketing, European University Cyprus, 1516 Nicosia, Cyprus; \\ k.gouliamos@euc.ac.cy \\ 4 Business School, La Trobe University, Sydney, NSW 2000, Australia; 20463989@students.ltu.edu.au \\ 5 Business School, The University of New South Wales, Sydney, NSW 2052, Australia; \\ z5174922@ad.unsw.edu.au \\ 6 Business and Economics Research Group, Ho Chi Minh City Open University, 97 Vo Van Tan Street, District \\ 3, Ho Chi Minh City 700000, Vietnam; ha.nm@ou.edu.vn \\ 7 Vice Chancellor, Siksha 'O' Anusandhan University, Bhubaneswar 751030, India; rpmohanty@gmail.com \\ 8 Rattanakosin International College of Creative Entrepreneurship, Rajamangala University of Technology \\ Rattanakosin, Nakhon Pathom 73170, Thailand; rice@ricechina.net \\ 9 National Institute of Development Administration, Bangkok 10400, Thailand; ruihui.pu@gmail.com \\ 10 Center for Research and Innovation in Business Sciences and Information Systems (CIICESI), Escola \\ Superior de Tecnologia e Gestão, Politécnico do Porto, 4610-156 Felgueiras, Portugal \\ * Correspondence: x.yue@external.euc.ac.cy; Tel.: +357-22713205
}

Received: 14 August 2020; Accepted: 28 September 2020; Published: 1 October 2020

\begin{abstract}
At the global level and in particular the European level, challenges related to climate change and the transition to green transactions have created an imperative where identifying or developing innovative financial instruments, appropriate for these priorities, have become our research priorities and objectives. Starting from the analysis of the European Investment Plan for green transactions, as well as the EU Directive 2018/410 of the European Parliament and of the Council, in conjunction with ongoing efforts to identify innovative financing tools, research is presented based on hypotheses using concepts and models of green financing. The paper aims to analyze the main concepts and phenomena that could be considered generative factors for current financial market trends, as well as the inventory of facts and acts that provide a picture of the financial market. Based on these investigations, this paper suggest how we can best analyze the economic environment, processes, and resources in terms of their predictions regarding the sustainability of financial markets in the context of current challenges. Moreover, our paper aims to highlight in our empirical research the above-mentioned aspects, including the analysis of the emergence of new financial instruments at the global level with a direct impact on financial sustainability at the European level, including reflecting certain particularities of financial markets Romania. This research will be both a scientific contribution to the specialized literature and a possible support tool for the practical activities of entrepreneurs in their economic endeavor of developing sustainable businesses.
\end{abstract}

Keywords: financial instruments; climate change; green transactions; sustainable development

JEL Classification: O16; P33; Q54 


\section{Introduction}

The theme of our research is determined by several elements. These include the emergence of new integrated financial technologies at national and international levels (e.g., digital financial technologies of fintech type and integrated financial services), the importance of the link between the evolution of financial markets and financing of the economy and the effect of these developments on the objectives of strategic financing at the national level, the emergence of new financial instruments on a global level with a direct impact on the sustainability of finances, and the emergence of decisions or directives that are based on concrete needs, respectively starting from principles to mechanisms and instruments.

The revised EU Directive 2018/410 mentions the principles for the operation of financing instruments and the Member States have to make important decisions about how the available funds will be used. The changes the Directive has made include the following: the Modernization Fund which has been established to support low carbon investments in the energy sectors of $10 \mathrm{EU}$ Member States with incomes below the European average, the establishment of the Innovation Fund, which all Member States can access. In addition, the financing mechanism for the modernization of the energy sector, the so-called Article 10c Mechanism, has been reformed and will be available for the same 10 low-income Member States, including Romania. In this context, each State's obligation was to define the allocation and specific means for the Article 10c Mechanism, or optional transitional allocation by publishing a detailed national framework and transmitting to the Commission elements specific to the mechanism. The required information includes the selection procedure and clear criteria for both large projects (over 12.5 million euros) and smaller projects.

Another EU-level decision that has had an impact on the development of financing mechanisms and financial instruments is the current program, the European Investment Plan for green transactions, which starts from the following considerations: increasing the financing for the transition and mobilizing an amount of at least $€ 1$ trillion to support sustainable investments over the next decade through the EU budget and associated instruments, in particular InvestEU. This has created a framework that will facilitate sustainable investments for private investors and the public sector, and has provided support to public administrations and project promoters in identifying, structuring, and executing sustainable projects.

The main objectives of this research are the analysis of global financial market trends, i.e., the emergence of new global financial instruments with a direct impact on the sustainability of finance at the European level, examining the functioning and organization of financial market processes for business (economic) and investigating the role of government programs and decisions in supporting the financial market at national and European level, highlighting certain features of financial markets in Romania. We have made some conceptual proposals and methodological assumptions regarding the path that SMEs should follow to obtain a sustainable financial source. The paper presents both current trends of the national financial market and the necessary (obligatory) character of the transition from the (current) optimality paradigm to the sustainability paradigm, the causal factor being precisely the phenomenon of the globalization of financial markets (the effect, in turn, of the optimality paradigm).

We also propose a list of the main financial trends at national and international levels, the concept of "green" financing and the network financial model. The second "green" concept mentions the relevant financial indicators that could affect the sustainability of financial sources, including the sustainable development of companies both nationally and globally.

The process of globalization inevitably leads to a review (conceptual reconstruction) of the paradigm of economic growth and development at local, regional, national, European, and global levels. Inevitably with a focus on the transition of the financial market toward green financing, the need to meet the challenge, on one hand, of the depletion and/or qualitative deterioration of resources (especially natural) and, on the other hand, of our optimization model - the maximization of the objective-functions at the level of economic-financial actors-is likely to signal a radical change of options, as well as means by which we approach this important activity of individuals and society. 
It is now evident that financial activity can no longer be considered to be a separate module, governed by discrete rationality distinct from others and based on a self-sufficient logic. The logic and rationality at the level of financial markets must accept, under the pressure of global problems, permanent and fundamental communication with the other logics of individual (social) behaviors (praxis). In addition, they must accept the possibility and desirability of some reevaluations, repositions, or even refurbishments considering the new paradigms regarding economic processes.

\section{Theories of Economic Growth}

More and more theories are emerging in the field regarding the challenges of financial changes such as those concerning the use of financial instruments in companies' activity and the use of transition financing tools. In view of the current financial reality (new digital financial products, new architectures of banking and non-banking financial institutions, new regulations regarding financing concepts, such as "green financing", etc.), the adaptation of financial systems to new technological trends is being evaluated, and budgets of EU funding programs for the period 2021-2027 have also been designed according to this context. Meanwhile, the new financial reality is reflected in new business concepts such as fintech. However, to adapt to these challenges, those using these technologies must understand the main "major technological trends, including cryptocurrencies, artificial intelligence, blockchain and large databases (information) from the business point of view and of regulations. Also, there should be aware of how to analyze and evaluate technological innovation in finance and how new technologies influence economies, markets, companies, and individuals" (Sanicola 2017). Financial technology has been used to automate insurance, transactions, banking and risk management (Aldridge and Krawciw 2017). Their services may come from different independent service providers, including at least one licensed bank or insurer. Interconnection is also possible through the API and openings in the banking sector, supported by regulations such as the European Payments Directive (Scholten 2017).

In the current technological challenges in finance, we consider that the decisive element is given by the development of sustainable financial instruments, mechanisms and networks. Sustainable finance examines how finance (investment and lending) interacts with economic, social, and environmental issues. In the role of allocating funding can help make strategic decisions on trade-offs between sustainable goals (Schoenmaker and Schramade 2019).

In 2018, it was estimated that globally, over 2.2 billion working-age adults did not have access to the types of official financial services provided by regulated financial institutions (Sanicola 2017). There is also some skepticism about the effectiveness of financial inclusion initiatives (Schueffel 2017). However, research on microfinance initiatives indicates that large availability of credit for microenterprises can produce informal mediation, a form of entrepreneurship (Aldridge and Krawciw 2017). The term "financial inclusion" has gained acceptance among scientific and world leaders since the beginning of 2000, when financial exclusion was identified as being directly correlated with poverty (Scholten 2017). The United Nations defines the objectives of financial inclusion (McWaters 2015) as follows: access to a reasonable cost for all households of a complete range of financial services, including savings or deposits, payment and credit transfer, and insurance services.

The EU's financial instruments for the period 2021-2027 have been established in accordance with the general objectives of the common policies: namely a more sustainable, inclusive, and innovative Europe. An important source of reference is the EU Budget 2021-2027, which describes itself as "A modern budget for a Union that protects, empowers and defends the multiannual financial framework for the period 2021-2027 (European Commission 2020a)."

The Green New Deal follows on existing initiatives at European level. For example, took place on 5 July 2007, the European Green Bank's first green bond issue under the name of EUR 600 million in climate awareness bonds, is known as the 'Awareness Bond'. This bond is aimed to offset expenditure on European Investment Bank (EIB) lending projects that contribute to climate action in the fields of renewable energy and energy efficiency. Renewable energy includes wind, hydro, solar and geothermal 
energy projects. Energy efficiency includes projects for regional heating, co-generation, insulation of buildings, and reduction of energy losses in transmission and distribution, and replacement of equipment with significant energy efficiency improvements (EIB 2007). Moreover, this comes in the current context of climate change, and for the Green New Deal and the Multiannual Financial Framework 2021-2027, the great challenge is given by the proposals of financial architectures, financial products, and networks. Researchers can propose in their working respective to come up with proposals from either scientific point of view or practical applicability.

In Romania, for example, the instruments could support the production of energy from renewable sources and through the System for promoting the production of energy from renewable energy sources through green certificates (accreditation was allowed until the end of 2016, the validity of the support scheme for accredited operators expires in 2032). These instruments provided in the framework of the Integrated National Plan in the field of Energy and Climate Change 2021-2030 (Ministry of Economy 2020).

To be able to respond to the established theme, we believe that a better understanding is necessary of the European Green Investment Plan (EGDIP), also called sustainable European investment plan (SEIP), as described by the EU representatives. The Plan (SEIP) represents the "green pillar of investment" and is one of the EU's current priorities. The Plan's definitive budget is "at least 1 trillion euros in sustainable investments in the next decade" (European Commission 2020a). Furthermore, the direction of action will be oriented on one hand along the fair transition mechanism, and, on the other hand, part of the Plan's budget will be directed to "investments of at least 100 billion euros between 2021 [and] 2027 to support workers and citizens from the regions most affected by the transition" (European Commission 2020b). Please see Figure 1.

\section{WHERE WILL THE MONEY COME FROM?}

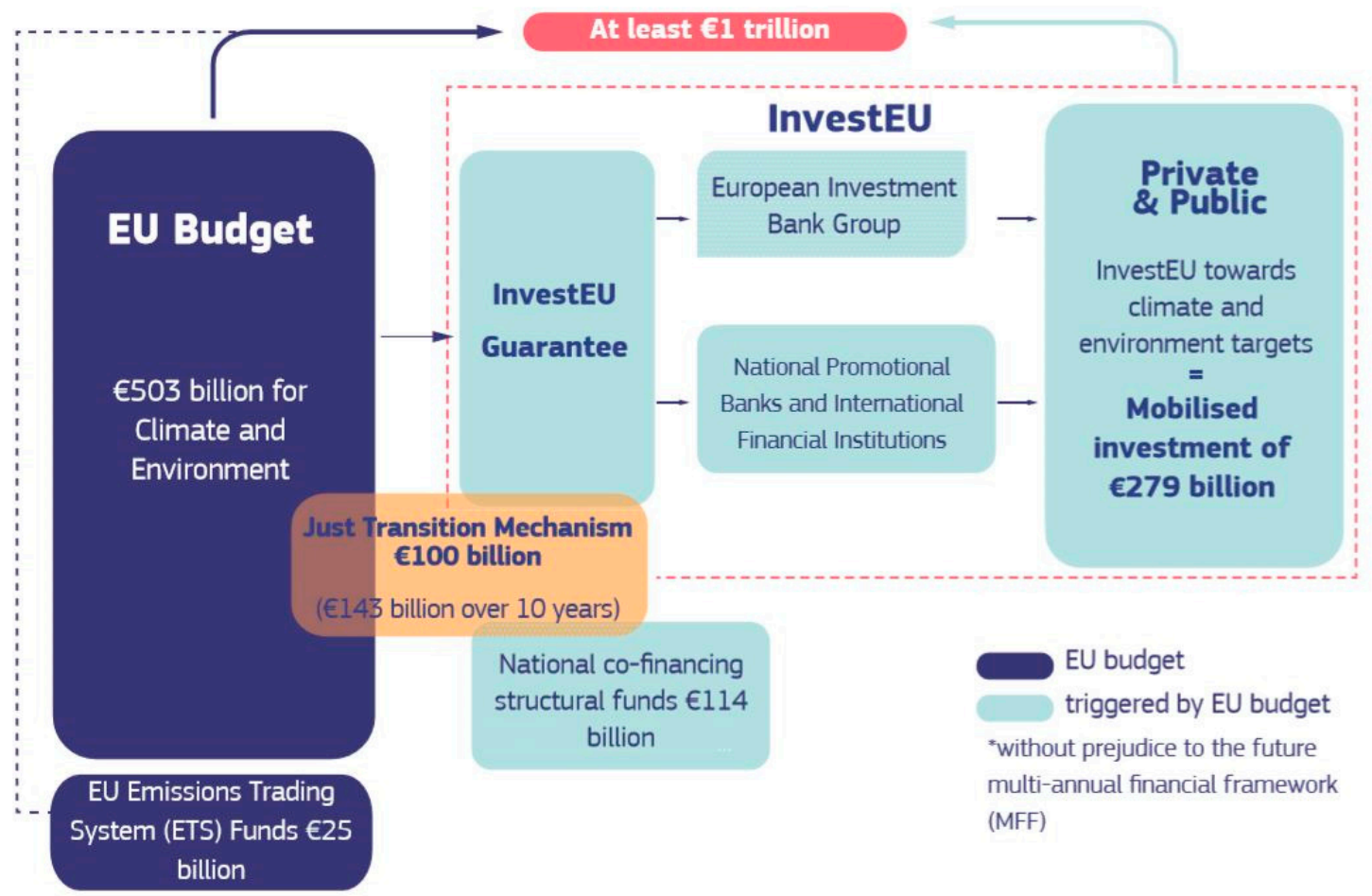

*The numbers shown here are net of any overlaps between climate, environmental and Just Transition Mechanism objectives.

Figure 1. Funding scheme of the European Investment Plan for Green Transactions (1 trillion euros). Source: The European Green Deal Investment Plan and Just Transition Mechanism, EU Brussels, 14 January 2020.

This EU-level challenge to become the world's first climate-neutral bloc by 2050 is also a great opportunity, for researchers worldwide, because the EU model can potentially be propagated elsewhere. 
Moreover, building the budget, mechanisms, and funding instruments by involving private actors in the Member States will play an important role in financing the European Green Agreement and in the functioning of the financing mechanism as a whole. A central regional budget combined with private financial industry actors may represent a strategy for coping with climate change and meeting its massive global investment needs.

The European Green Agreement is supported by the European Commission's multiple initiatives, such as the EC Action Plan on financing sustainable growth (2018), in which private investment has been channeled toward the transition to a climate-neutral economy, namely their financing through European programs. Sustainable finance considers environmental and social considerations when making investment decisions, which leads to an increased investment in long-term and sustainable activities. More specifically, environmental considerations includes mitigation and adapting to climate change, as well as the wider environment and related risks (e.g., natural disasters). Social considerations includes issues of inequality, inclusion, labor relations, investment in human capital and communities. The governance of public and private institutions, including management structures, employee relations and executive remuneration, plays a key role in ensuring the inclusion of social and environmental considerations in the decision-making process. Three components-environment, social and governance (ESG) - are an integral part of economic development and sustainable finance (European Commission 2018). These aspects determine us to reconsider the architecture of finance, in the context of sustainable financing. Moreover, they could be applied to identify the risks and to mitigate these risks through the adequate governance of financial and corporate actors.

The new EU budget for 2021-2027 is structured with substantial investments in climate and environmental objectives. Furthermore, "The Commission has proposed that $25 \%$ of its total contribution to climate action and environmental spending in several programs (for example, the European Agricultural Fund for Rural Development, the European Agricultural Guarantee Fund, the European Regional Development Fund, European Development Fund, Horizon Europe and Life Funds)" (European Commission 2020b).

Taken together and extrapolated from 7 to 10 years, assuming that the climate target after 2027 will at least be maintained, the EU budget will provide $€ 503$ billion to the European investment plan for green transactions. This will trigger additional national cofinancing of approximately $€ 114$ billion, over this period, for climate and environmental projects. InvestEU will use approximately $€ 279$ billion in private and public climate and environmental investments over the period 2021-2030. This will provide an EU budget guarantee enabling the European Investment Bank (EIB) Group and other implementing partners to invest in projects with higher risk, attracting private investors. Furthermore, "the Fair Transition Mechanism will mobilize at least $€ 100$ billion in investments from 2021-2027, with funding from the EU budget, co-financing from the Member State/States, as well as the contributions from InvestEU and the European Investment Bank (EIB). Extrapolated over ten years, the Fair Transition Mechanism will mobilize about 143 billion euros" (European Commission 2020a).

The financial instruments (green finance) were diverse at the level of international financial institutions. Among these instruments, "First ecological obligation of the World Bank" has received strong support from the initial investors of the pension funds. Since the first green bond, the World Bank has issued more than 135 green bonds, earning more than $\$ 10$ billion. Moreover, the World Bank's green bonds have been issued in a range of bond sizes, from the reference size issued in Euros, US dollars and Australian dollars, to private placements and smaller bonds for retail sale investors in 18 currencies over a range of maturities up to 30 years. The World Bank has been at the forefront of expanding its supply of green bonds. For example, Green Growth Bonds, ESG-focused green bond bonds, raised $\$ 530$ million from investors in Europe, the US and Asia. More than $\$ 650$ million has been raised through similar bonds, linked to investor equity. Other green bond issuers include the International Finance Corporation (IFC), a member of the World Bank Group, and the Development Business Bank (AfDB). IFC issued its first green bond in 2010 and reached the market $\mathrm{A} \$ 1$ billion benchmark green bond in 2013 (World Bank 2018). 
In the scientific literature, scholars have provided in-depth analysis of the green bond premium, namely Greenium, using both primary and secondary data of the trading market. These scientific papers reveals the relevance of the issuer's global reputation in terms of sustainability for the acceptance of environmental bonds by investors (Kaprauny and Scheinsz 2019) and (Helwege et al. 2014). Globally, trading platforms have been developed. For example, Cbonds platform is a global fixed income data platform on the bond market, which covers over 170 countries and 250,000 domestic and international bonds (http://cbonds.pl).

Last but not least, we should note "the funds for innovation and modernization, which are not part of the EU budget, are financed by part of the revenues obtained from a main policy instrument- the auctioning of carbon quotas within the EU. The emissions trading system will provide around 25 billion euros for the EU transition to climate neutrality with a special focus on the lower-income Member States in the case of the Modernization Fund" (European Commission 2020b).

To achieve the objectives mentioned in the Green Pact of the European Union, in addition to an operational mechanism for this plan, both at the European Union level and the local level in each Member State, as well as in relation to other non-member states, it is considered necessary to redefine the new architecture of the financial markets. This constitutes working hypotheses for researchers, such as our working hypothesis from the present paper, namely to try to redefine a new architecture of the financial markets. We consider that elements with a major impact on this redefinition are the digitization of banking financial services and automation of the banking financial profession, as well as the emergence of new financing instruments and models.

\section{Methodology}

We have used classical tools of observation and examination-research methods based on the basic principles of scientific research: "competence, objectification, truth, methodological, demonstration, correlation, evaluation of results, usefulness" (Ristea and Franc 2013). Our procedures are based on factual analysis-intensive documentation at the level of specialized literature both nationally and internationally.

The methodology of the empirical research was based on the collection of data and information from the literature and from the existing practice at the level of the European Commission institutions (funding instruments, recovery and resilience mechanisms in crises, rules on setting ceiling levels and on redistribution funding sources, the European Union's 2030 climate targets, the EU's 2050 climate neutrality target in line with the objectives of the Paris Agreement). Therefore, the data used in this paper were collected based on studies, papers and analyses identified by the authors of the research and reflected both by citation in the paper and by mentioning them in the chapter of bibliographic references.

The financing instruments and mechanisms exemplified by us had as reference elements the financing mechanisms detailed in the Green New Deal Act, the Multiannual Financial Framework 2021-2027 including part of the Green New Deal Act. A tool specific to the architecture of financial markets especially in the current context of the collaborative economy and highlighted by us is given by financial networks, a support tool especially in the context of transition to the collaborative economy through digital trading platforms, respectively new financing instruments and financial markets globally converging today.

Moreover, in the paper we analyzed the documents using comparative, analytical and descriptive methods that involve non-participatory and participatory observation, examining a set of information sources and collecting financial data in databases established at European and global level. The data were processed to provide an overview of the most important changes taking place, the analysis of global financial market trends and the emergence of new global financial instruments with a direct impact on the sustainability of finance at European level. 


\section{Results}

This study starts from two working hypotheses, namely highlighting the financial resources of the European Union (Green New Deal Act, the Multiannual Financial Framework 2021-2027 including part of the Green New Deal Act), and its own mechanisms and concepts on "Redefining a new architecture of financial markets". Moreover, through the "mechanism for a fair transition to better sustainability", a component included in both the Green New Deal Act and the Multiannual Financial Framework 2021-2027. Redefining the architecture of financial markets in the context of the Green New Deal Act, the Multiannual Financial Framework 2021-2027 is a hot topic of financial research. This study presents the four of its basic elements (i.e., Architecture of financial markets, the network of financial collectors, the Financial Investment Network and its many risks), which directly contribute to personal scientific literature and provide a solution for the institutions involved in management of the Green New Deal Act and the Multiannual Financial Framework 2021-2027.

\subsection{Presentation of the Fair Transition Mechanism and How It Will Be Financed}

Whereas the European Investment Plan for Green Transactions concerns how to support the green agreement as a whole, the fair transition mechanism particularly addresses the regions that the transition to climate neutrality will most affect, to ensure that the transition works well for everyone. The fair transition mechanism is structured around three financing pillars that are explained below:

Just Fair transitional fund: the new fund will be equipped with its own budget within the EU budget, which the Commission proposes to raise to 7.5 billion euros over its long-term budget proposal. The fund is covered by a new legislative proposal presented alongside the European one.

- $\quad$ The Green Deal investment plan. Member States will match each euro in the Fair Transition Fund with a minimum of $€ 1.5$ and a maximum of $€ 3$ from the European Regional Development Fund and the European Social Plus Fund. These resources from the EU budget will be further supplemented by national cofinancing according to the rules of cohesion policy. Taken together, the funding will reach between 30 and 50 billion euros in period 2021-2027. The fund will primarily provide subsidies to regions where many people work in coal, lignite, oil, and peat shale, or in regions that house greenhouse industries. For example, it will support workers to develop skills and competences for the job market of the future and SMEs, but also new economic opportunities for creating jobs in these regions. It will also support investments in clean energy transition-for example in energy efficiency.

- Transition scheme dedicated only to InvestEU to mobilize investments of up to 45 billion euros. This will attract private investments that will benefit these regions, as well as help their economies to find new sources of growth. For example, this could include decarbonization projects and the economic diversification of regions, energy, transport, as well as social infrastructure. The scheme will operate in accordance with the principles that define InvestEU, whereby part of the financing within InvestEU will be focused on fair transition objectives. The goal of generating up to 45 billion euros of investments corresponds to a supply of approximately 1.8 billion euros from the EU budget for the EU budget InvestEU program.

The public sector loan facility with the European Investment Bank, supported by the EU budget, mobilizes $€ 25-30$ billion in investments. It will be used for concessionary loans for the public sector-for example, for investments in energy and transport infrastructure, district heating networks, and building renovation or insulation. The loan facility will be based on a $€ 1.5$ billion contribution from the EU budget and a $€ 10$ billion EIB loan at its own risk. The Commission will present a legislative proposal for the creation of this new public sector lending facility in March 2020.

The right transition mechanism means more than financing. It builds on a fair transition platform, involving public authorities and private companies in developing business models where more than $25 \%$ of investment projects are "green investments". It also involves financial institutions in the creation of "green financing" models, which have a directly impact by supporting green investments 
and providing legislative support in regulating this mechanism so that it is correctly classified by policy makers and not affected by political decisions related to "green investments" or "green financing" programs. The Commission will also provide technical assistance to Member States, regions, and investors and make sure that affected communities, local authorities, and social and non-governmental organizations are involved. The platform will allow bilateral and multilateral exchanges of experience on lessons learned and best practices in all sectors concerned. The Commission will also facilitate investment in the transition by ensuring that the regulatory framework provides appropriate incentives.

\subsection{The Architecture of Financial Markets-Formalization}

Currently, with globalization of financial markets, trading is primarily virtual, and the role of researchers is to identify new financial instruments appropriate to this reality. We suggest that in the virtual financial space, markets tend to follow a network model.

Financial space is a monetary representation of all other areas that can be identified and defined in society, particularly in the economy, and can be considered to be a set of specific financial interconnections delimited by defining characteristics. The profound changes in interconnections between socioeconomic entities appear increasingly in specialist discussions in new information channels. These changes are presented not only as a series of problems related to the currency's virtual aspect, but also as financial risks related to the virtual space and the degree of "mastery" of information networks.

For a company to achieve its objectives in the short, medium, or long term, it must interact with its social, economic, and natural environments. The financial space is also dual, presenting two often contradictory assumptions: (a) all entities, channels, stocks, and collection flows, and (b) all entities, channels, stocks, and investment flows. In this context, we intend to analyze the components of the financial network and clarify risks that may arise in such types of networks.

\subsection{Financial Collector Network (RFC)}

This type of network, discussed by Dimitriu and Manta (2017), mobilizes currency availabilities from economic subjects who have financing capacities. The financial instruments for collecting are deposits (DP) and securities (TV).

Both deposits and securities are diversified, with maturities, interests, and modalities adapted to lenders' requirements and their needs to make the most of their availability. At the same time, the two types of instruments have specific techniques to cover the risks and protect the interests of the bidders from risks generated by the economic environment, by the banking entities, and by the investment instruments used to "invest" the collected availabilities.

Two categories of participants operate within this network:

(1) Bidders of availability (ODP), represented by households (GP), firms (FR), state (ST) and even financial institutions (IF). For methodological reasons, we did not consider "the outside" —-that is, financial relations with the subjects from outside the country.

(2) Collecting financial institutions (IFCs) that can be delimited according to two types of collection institutions (ISCs): banking institutions (IB) and nonbanking institutions (IN).

The banking institutions are universal and specialized (e.g., commercial banks, popular banks, savings banks, and investment banks). Their defining feature is that they generate monetary creation by transforming deposits into investment instruments (IPL). At the same time, these institutions also realize the cash flows and payments from the economy.

This deposit collection network (PDP) is strongly regulated and controlled mainly by the National Bank and banking institutions, which as a rule, establish parameters for the supply and demand balance of both short-term deposits (PDZS) as well as long-term deposits (PDZL).

The nonbanking institutions collect the availabilities using a variety of securities purchased by the liquidators, which are provided to investors-that is, those who need long-term liquidity. 
Disintermediation has led to the emergence of a diversity of such financial institutions, which have adapted their instruments to bidders' needs. Such institutions include insurance companies, pension funds, mutual funds, investment funds, and securities companies. These institutions deposit their availabilities at banks, constituting institutional deposits, with specialized management companies managing the funds.

The financial collection network is differentiated into various components, the most important of which include: the mutual fund sub-network (PFM), the insurance sub-network (PAS), the investment fund sub-network (PFI), the pension fund sub-network (PFP), and the mortgage sub-network (PIC). All of these connect through financial institutions within the placement network. As a rule, this network constitutes institutionalized liquidity (LIT), capitalized and consolidated through professional investment management.

A distinct subnet specific to the financial collection network is represented by the state collection network (PCT), through which the state procures its financial resources (with the help of the Public Treasury (TPB). This sub-network is divided into two components: the fiscal collection sub-network (PCF) and the sub-network of public loans (GDP). This sub-division does not mean segmentation, strict collection, banking institutions operating within the securities sub-network, or using financial instruments to attract the availability in deposits (certificates of deposit). In addition, in this network the Public Treasury acts as an institution that uses financial instruments to borrow from both the population and financial institutions, often constituting deposits. Figure 2 illustrates a simplified version of the financial collector network.

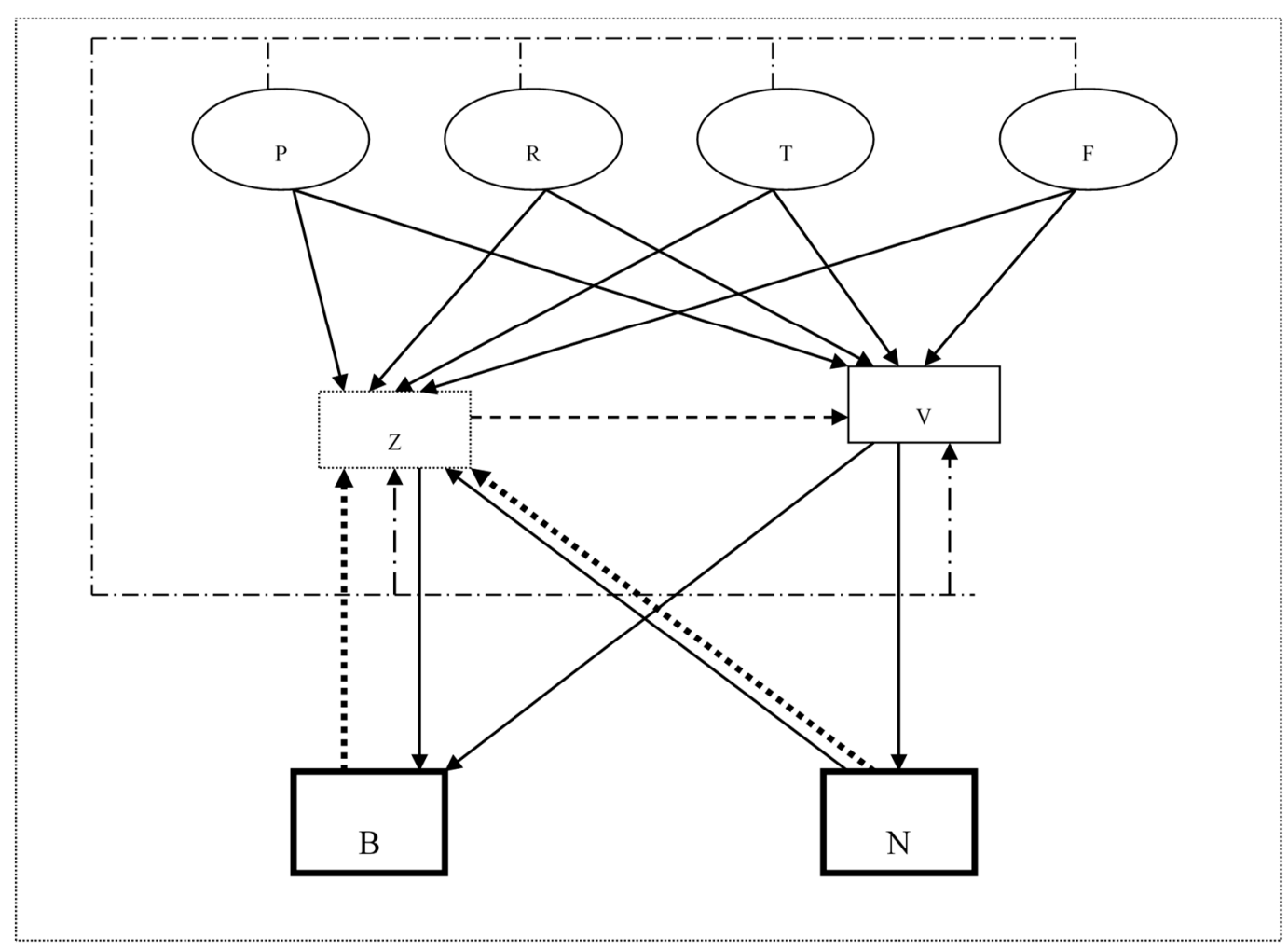

Figure 2. Collecting financial network.

This financial collector network, discussed in Manta (2018) and, Manta and Dimitriu (2017) suggests the existence of a targeted network:

- from the bidder to the financial institutions, the availability collected by the latter (DSB);

- from financial institutions to bidders, the "price" of loans for deposits, debt securities, and interest rates (DBZ). Cash flows collected in the form of deposits also involve withdrawal flows from banking institutions to bidders, or from conversion into securities. 
This network represents the institutional network (RID), which performs the availability drainage to the financial resource applicants (SRF). Interest rates on debt securities are obviously distributed through bank flows.

To avoid complicating the scheme, the withdrawals are highlighted by dotted lines.

We have made the following notations:

(DSB) $\mathrm{i}=$ total availability collected from each bidder;

(DSB) $\mathrm{ij}$ = the availability collected through both forms of instruments, DP and TL;

(DP) $\mathrm{f}=$ final deposits existing at banking institutions;

$\mathrm{DPD}=$ direct deposits of the bidders;

DPI = institutionalized deposits of financial institutions;

DPT $=$ deposits converted into securities;

(RIC) $\mathrm{k}$ = the remuneration of the financial instruments of collection;

$\mathrm{GNI}=$ unpaid remuneration of financial securities for collection;

$\mathrm{i}=1,2,3,4=$ bidder (GP, FR, ST, IF);

$\mathrm{j}=1,2=$ forms of collection instruments (DP, TL);

$\mathrm{f}=1,2$ = categories of final deposits (DPD, DPI);

$\mathrm{d}=1,2$ = financial institutions collecting by securities (IB, IN); and

$\mathrm{k}=1,2$ = forms of withdrawal of securities and securities.

Using the above symbols, the following relationships can be expressed:

$$
\sum_{i=1}^{4}(\mathrm{DSB})_{\mathrm{i}}=\mathrm{DST}
$$

where DST = total availabilities collected through financial institutions;

$$
\begin{gathered}
\sum_{j=1}^{2}(D S B)_{i j}=(D S B)_{i} \\
R_{i j}=\frac{(D S B)_{i j}}{(D S B)_{i}}
\end{gathered}
$$

where $R_{i j}=$ collection rate through each financial instrument, from each bidder;

$$
(\mathrm{DSB})_{\mathrm{j}}=\sum_{\mathrm{i}=1}^{4}(\mathrm{DSB})_{\mathrm{ij}}
$$

where (DSB) $j$ = the availability collected by the instrument $j$;

$$
\mathrm{R}_{\mathrm{j}}=\frac{(\mathrm{DSB})_{\mathrm{j}}}{\sum_{\mathrm{i}=1}^{4}(\mathrm{DSB})_{\mathrm{i}}}=\frac{(\mathrm{DSB})_{\mathrm{j}}}{\mathrm{DST}}=\frac{\sum_{\mathrm{i}=1}^{4}(\mathrm{DSB})_{\mathrm{ij}}}{\sum_{\mathrm{i}=1}^{4}(\mathrm{DSB})_{\mathrm{i}}}
$$

where $R_{j}=$ collection rate through the instrument $j$;

$$
\mathrm{DPF}=\mathrm{DPD}+\mathrm{DPI}-\mathrm{DPT}=\sum_{\mathrm{i}=1}^{4} \sum_{\mathrm{j}=1}^{2}(\mathrm{DSB})_{\mathrm{ij}}=\sum_{\mathrm{i}=1}^{4}(\mathrm{DSB})_{\mathrm{i} 1}+\sum_{\mathrm{i}=1}^{4}(\mathrm{DSB})_{\mathrm{i} 2}
$$

where DPF = final bank deposits; and

$$
\mathrm{R}_{\mathrm{f}}=\frac{(\mathrm{DZ})_{\mathrm{f}}}{\mathrm{DPF}}
$$


where $\mathrm{R}_{\mathrm{f}}=$ deposit rate (direct or institutional).

$$
\mathrm{DBZ}=\sum_{1=1}^{5}(\mathrm{DBZ})_{1}
$$

$\mathrm{DSB}_{\mathrm{j}=1}$, where $1=\left\{\begin{array}{l}\text { for } \mathrm{i}=1,2,3,4 ; \\ \mathrm{DSB}_{\mathrm{j}=2 .} .\end{array}\right.$

There are defined five interest categories (l), four related to the " $\mathrm{i}$ " bidders and one related to the bonds (TV).

$$
\mathrm{DPF}=\sum_{\mathrm{f}=1}^{5}(\mathrm{DPF})_{\mathrm{f}}=\sum_{\mathrm{i}=1}^{4} \sum_{\mathrm{j}=1}^{2}(\mathrm{DSB})_{\mathrm{ij}}
$$

and

$$
\mathrm{RIC}=\sum_{\mathrm{k}=1}^{2}(\mathrm{RIC})_{\mathrm{k}}
$$

where

$$
\mathrm{k}=1 \rightarrow \mathrm{RIC}_{1}=\sum_{\mathrm{l}=1}^{5} \mathrm{DBZ}_{1}
$$

and

$$
\mathrm{k}=2 \rightarrow \mathrm{RIC}_{2}=\sum_{\mathrm{i}=1}^{4} \mathrm{RTV}_{\mathrm{it}}
$$

where $\mathrm{RTV}_{\mathrm{t}}=$ the remuneration of securities t. Therefore,

$$
\begin{gathered}
\mathrm{RIC}=\sum_{\mathrm{l}=1}^{5}(\mathrm{DBZ})_{1}+\sum_{\mathrm{i}=1}^{4} \mathrm{RTV}_{\mathrm{it}} \\
\mathrm{R}_{\mathrm{k}}=\frac{(\mathrm{RIC})_{\mathrm{k}}}{\sum_{\mathrm{i}=1}^{4}(\mathrm{DSB})_{\mathrm{jk}}}
\end{gathered}
$$

where $R_{k}=$ the rate of remuneration of the collected availability, $k=1$ and 2 for $k=1$ :

$$
\mathrm{R}_{1}=\frac{\sum_{\mathrm{l}=1}^{5}(\mathrm{DBZ})_{1}}{\sum_{\mathrm{f}=1}^{5}(\mathrm{DPF})_{\mathrm{f}}}
$$

For $\mathrm{k}=2$ :

$$
\mathrm{R}_{2}=\frac{\sum_{\mathrm{i}=1}^{4}(\mathrm{RTV})_{\mathrm{it}}}{\sum_{\mathrm{i}=1}^{4}(\mathrm{DSB})_{\mathrm{i} 2}}
$$

Formalizing the collecting financial network can provide ways to determine inadequate "loads" of some network flows as a whole (availability, securities, and deposits) as well as "resistances" in the remuneration circuits determined by incorrectly managed rates. Effective regulation mechanisms can then be put in place. 


\subsection{Financial Placement Network (PPF)}

Through this network, the direct or mediated distribution of monetary resources to the entities that need financing is achieved. The demand equals the potential offer activated by financial institutions. The financial instruments comprise loans (CR) and securities (TPL).

The two categories of instruments are highly diversified and differentiated, adapted to the requirements and conditions of the demand for liquidity. This diversification is aimed at the "prices" attached, especially the interest, the risks that differentially accompany each type of instrument, the risks generated by the liquidity beneficiary (investor), the nature of the instruments, the management of financial institutions, and the economic business environment. The diversification is generated by the due dates, by the repayment modalities, and by the specificity of the financial institutions-but also by the nature of the clients, the investors, and liquidity destinations.

Loans and investment securities delimit distinct financial networks, differentially regulated, with the two categories of instruments sometimes overlapping one another.

Within the financial network, two categories of participants operate:

(1) Placement financial institutions (IFPs), which are usually collecting financial institutions (IFCs), but other institutions with investment-only activities, such as investment financial institutions (IFIs), are also included using the funds created or deposits in investment securities.

The following relationship can be written:

$$
\mathrm{a}(\mathrm{IFP})=\mathrm{a}(\mathrm{IFC})+\mathrm{a}(\mathrm{IFI})=\mathrm{a}(\mathrm{IB})+\mathrm{a}(\mathrm{IN})
$$

where a (IFP) represents the flows in the financial marketplace

(2) The applicants for financial resources (SRF), which represent the real demand for financial resources to invest in, where the applicants comprise mostly the companies (FR) and the State (ST) but also households of the population (GP) and financial institutions (IF).

The relationship between banking institutions and nonbank financial institutions is functional, with the sub-network segmented into the two interconnected compartments: credit sub-network (PCD) and the securities sub-network (PTL). However, this is a unitary network, in which the two categories of financial instruments transform into each other.

The credit sub-network comprises the interbank sub-network (PRP), the major component of the monetary network (PMT), the economic credit sub-network (PCE), which corresponds to the whole of the credits granted to the economy, the sub-network of public credits (PCB), the sub-network of consumer loans (PCS), and the sub-network mortgage (PCI).

Another distinct sub-network, connected to the sub-network of public loans, is represented by the sub-network of public investments (PIP). In this case, the state places, in various forms, the liquidity necessary to make investments in the economy. This sub-network is a component of the public placement network (PPB).

The securities sub-network (PTL) is further divided into the equity sub-network (CAP) which includes the securities and bond sub-networks (POB) which collectively form the securities sub-network (PVB), the short-term securities (PTT) sub-network, and other sub-networks.

However, the network of financial investments is divided not only by the nature of the instruments, but also by the ways in which their prices are set. The primary network (PPR) is where securities are sold by liquidity seekers who become the beneficiaries of the liquidities until the liquidation of the title often within the investor's portfolio. The securities are purchased through financial institutions by liquidity bidders, which may also be financial institutions, these being institutionalized placements (PLI) and different from private placements (PLP). The primary network is divided from this point into a primary network of private placements (PPPs) and primary network of institutionalized placements (PPIs).

The securities purchased are then traded within the secondary network (PSC), with the supply and demand generated by the bidders of availability. These bidders enter the stock exchange sub-network (PBS), an institutionalized form of the PSC, thus differentiating their financial resources by motivations (e.g., protection, earning, speculating, "ownership"). 
The sub-network of securities generates a type of risk "of distribution" with a special speculative load, often volatilizing securities of securities, values that become the object of transactions. This resulting sub-network is called the sub-network of derivatives (PDV).

The two types of investment instruments often, as mentioned, morph into each other, in particular with loans becoming investment securities, thus registering a disintermediation process which reduces the flows of loans in favor of flows of securities.

Thus, another sub-network is identified within the PPF: the sub-network of the transformation of placements (PTP) within which the securitization (PTR) is an essential component. These transformations take place both between types of loans and between types of securities. This sub-network is structural (PST) within the PPF and changes the structure of the placements. Beyond their interconnections, the differences between the two components of the financial placement network are self-evident.

The currency sub-network, or currency, can be considered an extension subnet (PEX) because it is controlled and regulated by the National Bank and other banks. The latter unilaterally establish the characteristics of the loans, especially their price-interest—which reflects the "balance" between financial resource supply and demand. This network is a network of intermediation in which the banks realize the transformation of deposits into loans. The intermediation thus breaks the monetary flow from saving (supply) to investment (demand), constituting a transit bridge, sometimes dangerous and often onerous. The banks, rather than the bidders or the applicants, control the risks, usually to their advantage, transferring most of the risks generated by the economic environment or by their own management, to the availability bidders (Yue et al. 2019).

The securities sub-network is much more open than the banking network, especially through its stock market component, where demand and supply of financial resources establish a much more transparent price, usually the interest rate. However, it is a much more risky, speculative, volatile sub-network. Figure 3 is a simplified diagram of the institutional setup, specific to the network of financial investments.

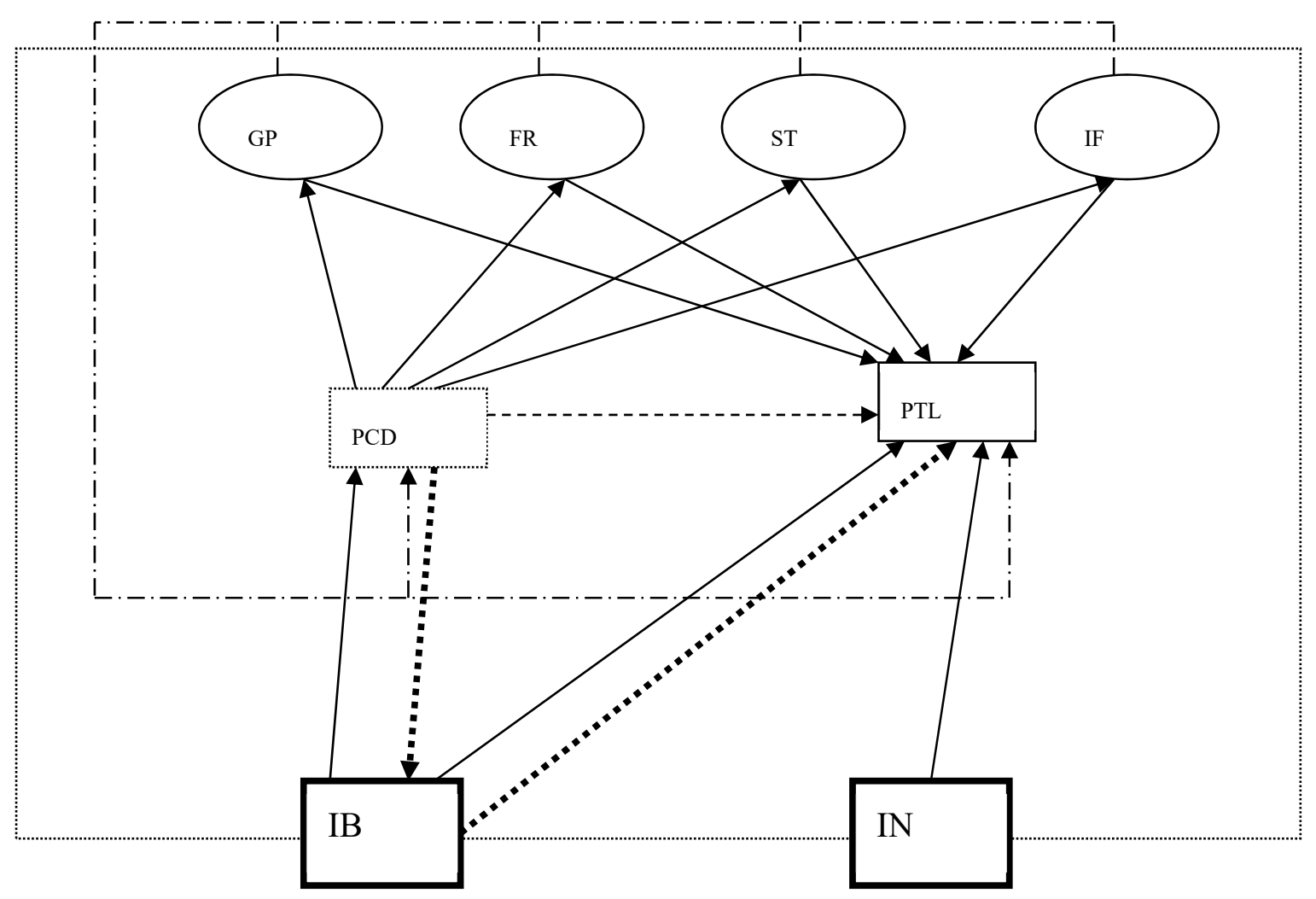

Figure 3. Summary of the components and interactions within the financial placement network. 
The simplified scheme highlights the existence of networks of univocally oriented monetary flows:

- from the financial institutions to the applicants for financial resources, especially the companies and the state, through the credits granted and the placement titles purchased on behalf of the bidders that the financial institution has collected;

- from the applicants for investments to the financial institutions where exist monetary flows through which the financial resources are reimbursed only to the due dates and at the same time the prices related to the placement instruments are paid.

Within the network of financial placements, the banks occupy the central place because all the monetary flows pass through them, both credits and securities (in this case the financial resources lodged are in the form of bank deposits), as well as the prices of the placement instruments and the returns of financial resources.

We have made the following notations:

(PLT) $\mathrm{i}=$ total placements, from the perspective of each applicant.

$$
\sum_{\mathrm{i}=1}^{4}(\mathrm{PLT})_{\mathrm{i}}=\mathrm{PLT}
$$

where PLT $=$ total investments (i.e., total financial resources obtained by the applicants).

From the perspective of PLT placement instruments, PLT is determined as follows:

$$
\mathrm{PLT}=\sum_{\mathrm{r}=1}^{2}(\mathrm{PLT})_{\mathrm{r}}
$$

where $r$ represents the two categories of placement instruments, credits, and securities. At the same time, the total investments can also be determined as the sum of the investments of the two categories of financial institutions:

$$
\mathrm{PLT}=\sum_{\mathrm{m}=1}^{2}(\mathrm{PLT})_{\mathrm{m}}
$$

where $\mathrm{m}=$ category of financial institution. The total financial resources (RFT) obtained by each of the four types of applicants can be determined as follows:

$$
(\mathrm{RFT})_{\mathrm{i}}=\sum_{\mathrm{m}=1}^{2}(\mathrm{PLT})_{\mathrm{mi}}=\sum_{\mathrm{r}=1}^{2}(\mathrm{PLT})_{\mathrm{ri}}
$$

This relationship requires verification:

$$
\sum_{\mathrm{i}=1}^{4}(\mathrm{PLT})_{\mathrm{i}}=\sum_{\mathrm{i}=1}^{4}(\mathrm{RFT})_{\mathrm{i}}
$$

Based on these indicators, several significant rates can be determined for characterizing the tensions and resistances in the institutional network of investments (RIP).

$$
\mathrm{R}(\mathrm{PLT})_{\mathrm{i}}=\frac{(\mathrm{PLT})_{\mathrm{i}}}{\mathrm{PLT}}
$$

This rate expresses the load of the financial resources flows to each applicant:

$$
\mathrm{R}(\mathrm{PLT})_{\mathrm{ir}}=\frac{(\mathrm{PLT})_{\mathrm{ir}}}{(\mathrm{PLT})_{\mathrm{i}}}
$$


where $r=$ the placement instrument used. This rate reflects the distribution of financial resources to the applicant and the two placement instruments.

$$
\sum_{\mathrm{i}=1}^{4} \sum_{\mathrm{r}=1}^{2} \mathrm{R}(\mathrm{PLT})_{\mathrm{ir}}=1
$$

The following notations are used: RTP = total remuneration of placement instruments.

$$
\begin{gathered}
\mathrm{RTP}=\sum_{\mathrm{r}=1}^{2}(\mathrm{RTP})_{\mathrm{n}}=\sum_{\mathrm{i}=1}^{4} \sum_{\mathrm{r}=1}^{2}(\mathrm{RIP})_{\mathrm{ir}} \\
\mathrm{RIP}=\sum_{\mathrm{r}=1}^{2} \sum_{\mathrm{m}=1}^{2}(\mathrm{RIP})_{\mathrm{rm}}
\end{gathered}
$$

The two relationships highlight the contribution of each applicant, instrument, and financial institution to the total remuneration of the investments. We note that CRT $=$ the total remuneration coefficient of the placement instruments

$$
\mathrm{CRT}=\frac{\mathrm{RTP}}{\mathrm{PLT}}=\frac{\mathrm{RTP}}{\mathrm{LCT}}=\frac{\sum_{\mathrm{i}=1}^{\mathrm{n}}(\mathrm{RTP})_{\mathrm{i}}}{\sum_{\mathrm{i}=1}^{\mathrm{n}}(\mathrm{PLT})_{\mathrm{i}}}
$$

Depending on the network's analytical requirements, the rates and coefficients can, therefore, be detailed indicators.

Formalizing the network of financial placements offers ways to determine "loads" of flows of the networks as a whole (availability, securities, and deposits) and of "resistances" in remuneration circuits determined by incorrectly managed rates. As in the case of the financial market, monitoring via the proposed indicators, one can intervene to fine-tune through regulation how the market functions.

In the context of redefining the architecture of financial markets and financial products by default (in our case the concept of green financial product-FinGreenTech), these concepts on the architecture of financial markets and financial products, the presentation of network risks and the principles of globalization, can support our argument for framing our results in the current context of the globalization of financial markets, especially through existing funding programs at European level.

The financial network is susceptible to several risks. Accepting the standard definition of risk as the probability of an event with adverse effects for the economic subject, the network risk in the financial space can be defined as the probability of the occurrence, triggering, and fulfillment of a network incident, which may affect the favorable achievement of the financial network's characteristics and interactive flows. Network risk is a flow risk, which disrupts or inhibits the interconnectivity and interactivity between elements of the network, constituents, distributors, or transients, with effects suitable for fulfilling the financial network's characteristics.

Exposure to network risk represents the potential or actual value of losses directly or indirectly generated by the deterioration of these characteristics, as a measurable amount, by which the expected revenues are diminished or the expenses incurred increased to reflect normal standards under the conditions of the adequate realization of the network's characteristics. Adequate realization of the network's characteristics is when the network's functional state assures the conditions of its fulfillment. This is when the interactive realization of the flows for capitalizing on the functions and potentialities of the monetary forms of the financial assets occurs through transfer of financial and monetary instruments. 
From the perspective of the characteristics of flows and of the network, a risk of the monetary network is in its institutional characteristic, which is determined by the dysfunctions arising from the network's institutionalization and interactions of its financial market flows.

The financial network achieves its defining purpose, or the dynamic balance between the demand and supply of currency, under the conditions of the institutionalized markets, within which the elements of the network are regulated, organized, coordinated, supervised, and even controlled within a system of relations, attributes, and differentiated responsibilities of network entities. The system is equipped with rules and procedures regarding the instruments and operations. The quality of the market institutionalization determines the functioning of the network, where network risk is a consequence of an inadequate network institution.

According to the definition and delimitation above, the network risk in the financial space has some distinguishing characteristics, the most relevant being the following:

- It is a risk that disturbs the interactivity of the network flows, affecting the force of the interactivity and of the active, distributive, and transitive transfers between the elements of the network, especially among its constituents: interactivity that gives the network individuality, potentiality and purpose.

- It is a risk that affects the interconnectivity of the network, its connections, the connections among the elements that allow and favor the realization of the interactivity, and the risk of decoupling, distortion, debilitation, and phase-out of these connections, and the interconnectivity contributing to network coherence, consistency and validity. This characteristic is materialized, for example, by affecting the interfaces and the nodes, the financial centers for coupling and connecting, and the monetary conversion operators.

It is a risk that manifests itself by altering the characteristics of the flows and the network in a way that threatens the authenticity of the network. From the perspective of this research, the risk affects a characteristic that is risk-bearing, a risk that regardless of the altered characteristic, induces disturbance of interconnectedness or interactivity, diminishing the active capacity of the network to transfer and transform the currency and monetary forms, through the distributive instruments and transitive operations.

It is a risk of triggering, accompanying, and consolidating risks specific to the monetary and financial space (e.g., the diminution of the coagulation force of the network). It can trigger risks such as liquidity risk, lack of funds, or, in another context, the risk of noncoverage, correlated with the course, in which financial risks are consolidated determined by the internal or external environment of an entity or by the inadequacy of the financial instrument.

It is a risk of propagation, contagion, and perpetuation of all the risks specific to the financial space (e.g., the decoupled network increasing the possibility of the occurrence and extension of the interest rate risk or of insolvency). It is also a contagion, assuming the generation, by interactivity disruption, of specific risks, favoring the inclination and preference for risk of network entities.

It is a risk generated by the form of realizing interactivity, by way of establishing the interconnectedness of the financial space-in other words, a risk determined by institutions and rules that is manifested in markets within the network of interactivity.

These features of network risk underline the fact that, as a human creation, even if it is a social determinant, the financial network is constituted in institutional forms. In this sense, the network risk is caused by the dysfunctions of the forms by which the network is formed.

This characteristic is defining, but not essential, for the risk in the financial network. In this sense, the action of network risk is revealed as an action to promote the propagation of specific risks.

This promotion is achieved through three channels:

The channel produced by the configuration's incompleteness and the organizational insufficiency of the network and its entities, in which the network is unable to carry out the transfer of monetary forms and financial instruments according to its aims or potential. This incapacity can be constituted as 
a result of the central public entities, determined by their organizational attributes or the configuration topology, with which it was endowed by institutional regulation. Or it can be an inductive incapacity that is, induced by the environment, by the monetary system or by the connections with other economic or social systems.

The channel resulting from the inadequacy of the network, the compositional inconsistency and the lack of representation of interactive flows, lead to a lack in the network, which does not have adequate financial instruments or currency forms. Moreover, the time for carrying out financial transactions, their transfer flows, the interactivity that does not sufficiently reflect or distort, the actual requirements of the monetary transfers through the available instrument, are also elements that define the importance of the financial network. In this sense, for example, the lack or shortage of commercial credit instruments, as well as the weak institutionalization of nonbank financial flows such as mutual funds, may favor risks of blockage and bankruptcy.

The channel resulting from network inactivation, operational delays, and disconnection of the circuits, incorrect network operation, invalidated currency transfers (e.g., network operation without sufficient substantiation or risk coverage), and failure to ensure compatible execution of all flows of the complete circuit of monetary forms or financial instruments. The manifestation of specific risks of this channel are facilitated by the action of the other two channels, of the interactivities, configurationally, and of the interactions, compositionally (He et al. 2019).

Favoring, through the three channels, the propagation of the specific risks in the monetary system, the network risk and its concrete forms have adverse effects, generating network losses and resulting in financial network recovery and rehabilitation costs.

The effects of network risk can be divided into the following complementary categories:

Direct effects, which affect the network--generally speaking, the ability of the network to adequately perform the transfer of currency forms and the fulfillment of the interactive flows that constitute the essence of the network. These effects can be distortion, weakening, decoupling, or phase shifting, but they may also take other forms that affect the financial network's institutional functionality. The accumulation of these effects, the creation of a functional adversity spectrum, can cause the network itself to become a generator of adversity. Despite attempts to solve its own dysfunctions, the network may enter the "dissipation" phase, in which it forms nodes, such as hedge funds or blockages. This can often lead to its serious deterioration under the conditions of propagation, contagion, and perpetuation resulting from concrete forms of network risk that trigger the other category of effects.

Indirect effects, induced by institutional dysfunctions through the specific risks of the financial network and interactive flows. These effects, triggered by the network risk and its concrete forms, take the intermediate form of risks specific to the financial network-risks that directly generate losses and incur costs. This category covers a variety of distinct effects: generating losses and costs, such as depreciation of currency forms, bankruptcy of financial entities and volatilization of financial instruments (e.g., shares, certificates of participation, and diversion of liquidity).

\section{Principles of the Process of Globalization of Financial Markets}

1. The main principles of globalization were defined by Zonis (2000):

2. The principle of "increased exposure to political risk": Banking financial institutions that extend across national borders increase the uncertainties they face.

3. The principle of "increasing the activity of multinational companies": Raising a larger community of standards and businesses beyond national borders, improved profits and market share can be achieved through mergers and acquisitions, faster than with conventional construction operations.

4. The principle of "identifying new forms of competition and cooperation": Financial institutions entering foreign markets will create new forms of competition.

5. The principle of "new cultural sensitivities": Global travel means improving efficiency and profitability by capitalizing on the world's best available talent. 
6. The principle of "common virtual space": As companies (including financial institutions) expand their geographical operations, managers are responsible for staff from different countries.

7. The principle of "best practices": Acting as a single company with a global, supranational culture excuses justifying the maintenance of national practices, which disappear.

8. The principle of "alliances": Globalization enables many new types of alliances.

9. The principle of "finance": Globalization leads to the harmonization of the functioning mechanism of the financial markets by uniformizing the levers, instruments, techniques, methods, and legal framework of operation.

10. The principle of "globalization of suppliers": a company's decision to globalize its entire supply chain, which affects all the companies that provide services.

11. The principle of "winners and losers in globalization": While globalization will provide huge aggregate benefits to both producers and consumers, it will not provide these benefits equally.

12. The principle of "returning from globalization": the transition to globalization for countries will not be easy or smooth. Inevitably, a reaction will be generated against globalization that will organize and press the State to resist globalization if not reject it outright.

\subsection{Financing and Economic Instruments}

In our opinion, the European Union must use the full range of financial policy instruments to implement its policies. The most appropriate economic instruments should be used to promote market transparency and prices that reflect the real economic, social, and environmental costs of products and services. Their potential to reconcile environmental protection and smart economic growth as well as exploit the opportunities offered by new technologies should be recognized and promoted, including through financial mechanisms. In addition, their suitability should be evaluated based on a set of criteria, including their impact on competitiveness and productivity. Member States must consider additional measures to transfer the taxation of labor on energy and/or pollution resources and consumption, while contributing to the EU's goals of increasing employment and reducing the impact on the environment in a cost-effective way.

\subsection{New Instruments That Should Be Developed in the Financial Markets, in Line with Sustainable Development}

Clearly, financial markets should develop techniques, methods, and tools consistent with the concrete conditions under which the global economy operates, or will have to operate. To achieve this, we propose the following.

\section{Concept of "Financing Green": FinGreenTech}

Financial activities enhance the financial industry, improve the environment, and promote economic growth by stimulating activities with ecological impact. A summary of how 'Green Financing' interacts with the broader financial industry is shown in Figure 4.

Green growth means from our point of view:

- a paradigm of economic growth that simultaneously pursues the environment's growth and improvement;

- stimulation of economic growth and job creation through research and development in the field of clean energy and green technologies;

- conservation and efficient use of energy and resources;

- mitigation of climate change and environmental. 


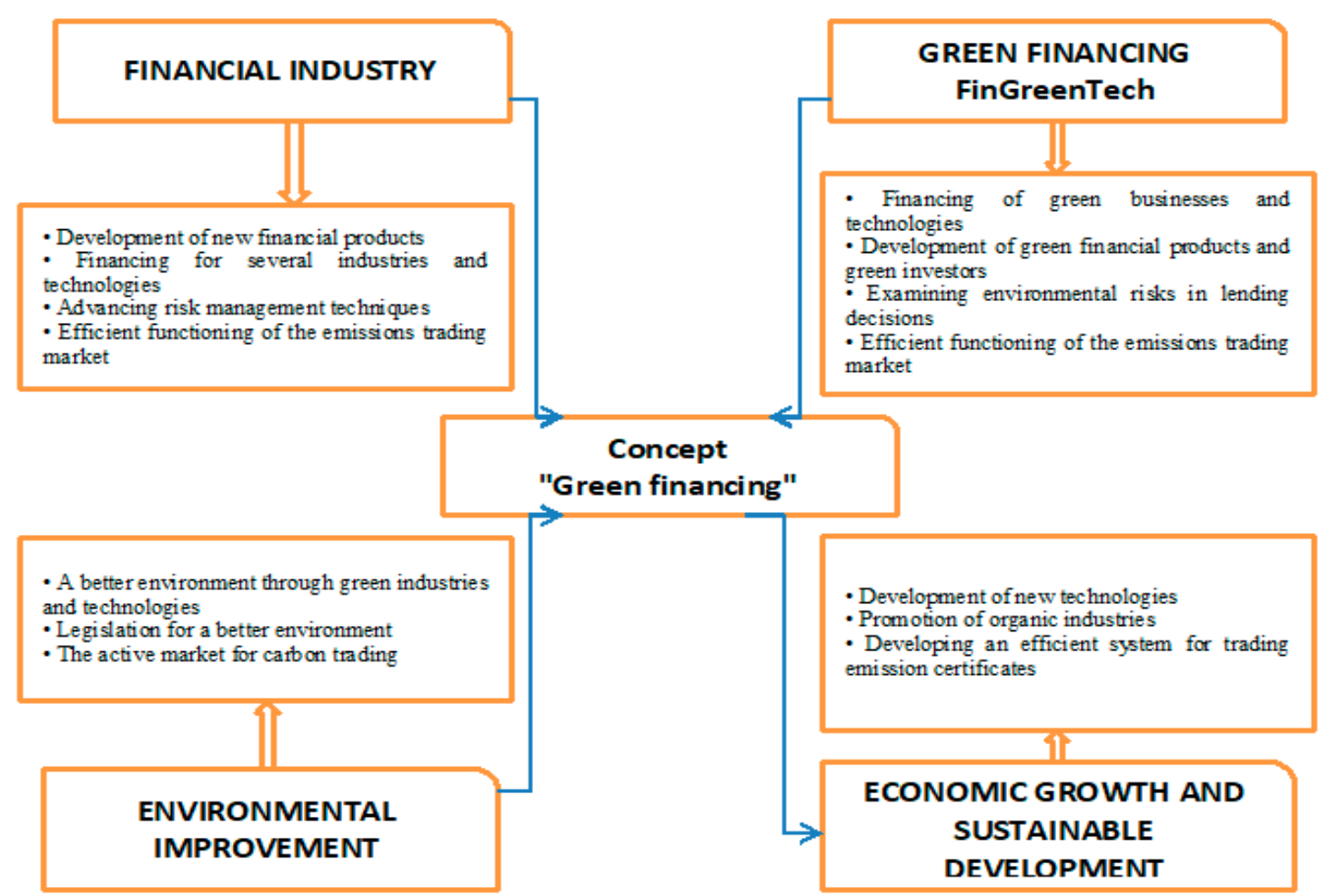

Figure 4. The concept of "Green Financing" and how it connects with the broader financial industry—using the FinGreenTech package as an example.

\subsection{Green Technology}

Green technology supports ecological growth by conserving energy and resources in various social and economic activities with a direct impact on environmental improvement. Greenhouse gas emission reduction technology minimizes polluting greenhouse gas emissions and promotes energy efficient technology, clean energy production technology, resource recycling, and green technology (including relevant convergence technology).

The Need to Develop the New Concept of Green Financing-FinGreenTech

Green industries based on green technology are promising growth sectors and, under the Paris Agreement, governments are required to fully implement green financial policies. Moreover, economists have launched the new concept of "green transition" as an extension of the concept of sustainability.

\section{Discussion}

The analysis of the evolution of the current situation of financial market trends provides a picture of the emergence of new financial technologies at national and international levels (fintech digital financial technologies and integrated financial services).

Identification of the financing need is directly related to the need to ensure stability of financial markets, through a system that monitors the use of financial instruments. The analysis also requires us to focus on the financial system as a whole, as it is essential to identify potential sources of instability, to limit risks, and avoid the high exit costs from potential major risk situations in global financial markets (Han et al. 2019).

The national financing programs, supported through the State aid instrument, can contribute actively and sustainably to the strategic sectoral development of the Romanian economy. This is possible in full compliance with the EU directives regarding state aid to the Member States. Therefore, it is necessary that these methods of supervision, through the combination of monitoring and regulatory 
activities, are relevant to the conjuncture considered in accordance with the objectives and are reliable, easy to apply, and standardized.

The financial market infrastructure plays an important role because financial stability is highly influenced by the environment in which financial intermediaries operate. Just as there are cultural differences between countries, there are also structural differences. Nations have diverse political and economic systems, legal frameworks, and tax structures, all of which play a central role in the development of their financial systems. Those national influences can certainly interact and affect practices and procedures at the level of regional financial markets.

Certain risks of financial instability are likely to occur from time to time. Therefore, formulating a well-articulated strategy for potential financial imbalances should be a priority for central banks and supervisory authorities. Such strategies should cover the following areas: a consistent policy framework at the macroeconomic administrative level that will ensure implementation of a coherent macroeconomic policy framework, an essential aspect for maintaining financial and monetary stability. The framework should also be consistent in achieving macroeconomic objectives and should avoid the accumulation of imbalances that can lead to instability.

At the regional level, the adoption of common standards in the direction of increasing levels of adherence and convergence to the standards of quality and practices is one of the key ingredients for efficient allocation and use of economic resources. It is also expected to lower the costs of capital and reduce appeals to the arbitration chamber, relating to regulatory matters. With increasing economic interdependencies, financial intermediaries must operate on a much broader field. This is important to consider both in terms of the potential for increased risk and the need for timely implementation of programs - especially programs that specifically target both regional and cooperative arenas. These strategies should also encourage the development of efficient and prudent internal risk management systems, and the State should, through appropriate policies, ensure that they are properly monitored and managed to avoid risks and increase transparency.

Market discipline, as another essential and indispensable element of ensuring financial stability, must be promoted through prudential regulation and supervision. This will allow and require the market to carry out specific activities within a framework associated with the need to ensure financial stability. Moreover, the correlation of fiscal pressure with market potential is crucial to ensure macroeconomic stability. The central problem of this analysis is that of macroeconomic stability-as a necessary condition for economic evolution at the level of current general problems. This stability also relates to the general problem of correlation between the elements of macroeconomic strategy and potential of the market. The correlation of the amount of taxation with the absorption capacity of the fiscal pressure at the level of the economic agents in general and, at the level of the SMEs, in particular, indicates an absorption capacity close to the general market capacity to absorb economic shocks to ensure macroeconomic stability.

With regard to global financial market trends and capital markets in Europe, the following points are relevant:

- There is a period of continuous economic growth, despite a slowdown in rhythm. There is also synchronization of economic cycles, which also proves that what we call connectivity is intense in the global space and not in the chain of "production chains." However, the global economy also has major vulnerabilities, and connectivity itself is a systemic risk.

- Protectionist tendencies pose a great danger by adding to the use of exchange rates as means of stimulating exports (to support the domestic economic activity). A trade war is no longer a hypothetical risk, and we see the amount of uncertainty increasing (as the IMF also warns). This danger adds to Brexit and Italy's risk in the Euro area.

- A narrowing of the nonstandard operations of large central banks (the EDF in particular) can be observed as a result of inflationary pressures and the desire to limit the undesirable effects of these operations. However, normalization will be very gradual, especially in Europe. 
- Even if "normalization" of monetary policies is gradual, shocks will be felt by the more vulnerable emerging economies through capital flight and increasing margins on loans. In this context, there is the danger of "syncope of access to liquidity" for economies that have large debts (especially external) and internal deficits.

- In today's uncertain global climate, Europe needs a monetary union that can withstand future economic shocks and enable the euro to play a stronger international role.

- Significant progress must be made in reducing risks in the banking sector and reducing the rate of nonperforming loans in European banks.

- Financial stability in the EU has been considerably strengthened, and risks for the banking sector continue to decline. In particular, for one year (2017), the average rate of nonperforming loans in the EU decreased by 1.2\% in 2017 compared with 2016, so that it reached 3.4\%. In Croatia, Cyprus, Hungary, Ireland, Portugal, and Slovenia, there were even decreases by $3 \%$ or more. However, in Greece and Cyprus there were very low rates of nonperforming loans, of about $45 \%$ and $28 \%$, respectively.

- From our point of view, we believe there is no need to give up firm regulation and supervision of the financial system. "Parallel markets" must be regulated, and financial technologies such as fintech are important, but we must not see them as a miracle cure. It is necessary to change the institutional culture of the global financial industry.

- At the international level, new financial products are emerging that are based on the concept of "green transition" and "green financing", in accordance with sustainable development.

We believe that for the financial markets, we should develop techniques, methods, and tools that are in accordance with the real conditions in which they work, or must work globally.

Through globalization, countries, financial markets, and economies are becoming increasingly interconnected: international value chains are emerging and are restructuring the international division of labor as well as the interdependence between countries, especially in international financial relations. Financial market trends are directly influenced by transparency obligations related to monetary conversion practices.

From the analysis of macroeconomic efficiency as presented in this paper, as a factor of the sustainable development of the financial market in Europe in period 2020-2038, we have developed two categories of conclusions and final remarks concerning theoretical-methodological and practical-applicative aspects.

\section{Conclusions}

\subsection{Theoretical-Methodological Aspects}

Theoretical-methodological conclusions refer to the direct involvement of macroeconomic efficiency in sustainable development principles and criteria aimed at:

- sustainable development for all of us, as a requirement of reducing economic and social inequalities and of inter and intra-country convergence;

- the principle of prevention, as a factor in saving resources and increasing economic efficiency, including financial resources;

- the principle "the polluter pays in full the damages (negative externalities)", generated for the third parties, on different time horizons;

- the principle of public-private partnership;

- intersectoral, interregional, and interstate cooperation;

- the principle of the "critical mass" of investment;

- the principle of subsidizing the positive externalities in the production of goods and services of public and private character; 
- the principle of involving all the members of the company and of financial or other participation in the cause of sustainable development;

- decoupling economic growth from the consumption of environmental resources;

- the principle of circular economy throughout the production and consumption processes;

- the principle of "win-win" cooperation, amended with the requirement of the equivalence (equality) of efficiency for each participant in the cooperation in the sense of achieving benefits, advantages, or profits commensurate with the efforts made;

- the principle of social responsibility and business ethics.

The above principles require further development because, as a rule, they interfere with or create a series of synergistic effects and inverse connections. These require taking into account the time factor as an economic value, based on specific updating rates, as well as the transition from linear to nonlinear models, based on multiple, intra, and interdisciplinary approaches. This development also involves paying greater attention to risk and uncertainty management of vulnerabilities, and to increase the resilience in the different categories of external and internal shocks.

Following this project to identify the trends of the financial market, a challenge in the field of scientific research is to create an economic model using the concept of FinGreenTech, and as research topics for the case of Romania, we mention the following:

- development of the technical infrastructure, the creation of the vector of "green" indices, and the development of the "index of green companies" in order to promote ecological investments;

- creation of the financing mechanism and a system for providing information on green technologies;

- the creation of "packages" of green financial education for the human resources involved in the green financing process;

- development of new financial products that integrate environmental factors into existing products and that take into account environmental technologies and risks in lending decisions; and

- development of new financial instruments that combine banking, insurance, and investment banking features.

In this context, we note the need for reindustrialization, based on knowledge to increase the degree of diversification of the national economy both as a reaction to its reduction during the transition period and as a result of the impact of (a) scientific and technological progress and (b) the digitization and computerization of the economy and society.

\subsection{Practical Applications}

The current financial situation at European is the result of a series of vulnerabilities, marked by significant disparities between the Member States of the EU. The degree of financial intermediation is low. The banking system has faced lending restrictions, as well as a high level of non-performing loans. The costs of bank financing from commercial banks are high. Public debt has accelerated and external debt has increased significantly in the pre-accession and post-accession periods. The international investment position is the innovation indicator followed by the European Commission, in which for example, Romania exceeds the alert threshold. Maintaining financial stability at Member State level would create the preconditions for an active interface between the real and the nominal economy at different levels of aggregation, micro and macroeconomic, over different time horizons, so as to create profitability and efficiency for all categories of stakeholders. This would be compatible with criteria, standards, principles and practices of maximizing and the dynamic balance of the inflation rate, the growth rate, the interest rate, the exchange rate and the yield on government securities. It would also encourage an understanding of "sustainable development for the benefit of all citizens, in the direct sense of efficiency and financial inclusion" (Annicchiarico and Giammarioli 2004). Ensuring financial stability and increasing the contribution of financial intermediation services to the financing needs of sustainable development implies the application of a coherent development 
strategy at European level in the next 20 years. In this context, we consider that both the Green New Deal Act, Multiannual Financial Framework 2021-2027 and financing models such as the concept of green financial product-FinGreenTech, can contribute to the sustainable development of the financial market of European and implicitly at local level. Over the next two decades, it is estimated that an increase in the degree of financial intermediation will reach 110-120\% of GDP in 2038, which will increase the efficiency of capital allocation and the contribution of the financial system to the sustainable development of each European state. Under the banking system, the loan-to-deposit ratio is projected to increase by $110-115 \%$ in 2038 , with a reduction in the non-performing loan rate (to $1-2 \%$ in 2038) and the costs of bank financing.

Based on personal determination, verified in practice, each state must ensure the soundness of the internal and external financial framework. Achieving sustainable economic growth in the coming decades requires maintaining a degree of internal and external indebtedness within sustainable limits. The timing of repayment terms and the extent of the annual service are correspond to the actual ability to make payments, and the participation of each state must be active under the Green New Deal Act and the Multiannual Financial Framework 2021-2027. This can be done by achieving a long-term debt-to-GDP growth rate, respecting the principle of intergenerational equity, and actively involving each state with innovative financing products and services green. It is expected that the positioning of the public debt, between 38 and $40 \%$ of GDP, will ensure a constant sustainability throughout the reference period. With a reduction in the public debt burden, the annual service will be between $15 \%$ and $20 \%$ of budget revenue in 2038 according to the Maastricht Criteria (Nominal Convergence Indicators). Moreover, according to data published by Eurostat, it is estimated that external financial stability will be maintained by reducing the share of GDP in external medium- and long-term debt by $30-35 \%$ by 2038 . The annual service will account for $15-20 \%$ of foreign exports goods and services until the end of the reference period 2020-2038. Economists' long-term estimation for the world economy seem rather bleak, especially when all resources are analyzed together. Defective debt and the resulting collapse in asset prices are of concern. This study provides the pragmatic solutions that could be considered in the Green New Deal Act and the Multiannual Financial Framework 2021-2027, and it also comes with scientific contributions respectively the Architecture of the financial markets, the Network of financial collectors and the Network of financial investment. Moreover, the latter provide a future avenue and worth further explore, especially in the context of current global challenges in the financial market, with direct examples in the context of global climate change.

(Brown 2012) asks several questions, for which answers have not yet been found-these include:

- "Will current policies generate a viable future or a collapse?"

- "Do new technologies have the power to influence the long-term trends of global systems, so that they grow or collapse?"

- "Is the free market capable of distributing resources to ensure a viable future?"

- "The market seems to allocate the riches of the rich and emphasize the poverty of the poor. What changes this component of the global system, without which it seems impossible to stabilize population growth?"

- "Can people in industrialized societies learn to live in harmony with nature?"

Author Contributions: Conceptualization, O.M., J.K., Z.L. and X.-G.Y.; methodology, O.M., R.P. and X.-G.Y.; software, O.M.; validation, X.-G.Y., K.G., N.M.H., R.P.M., H.Y.; writing-original draft preparation, O.M. and X.-G.Y.; writing - review and editing, J.K. and X.-G.Y.; funding acquisition, O.M. All authors have read and agreed to the published version of the manuscript.

Funding: This work has been supported by national funds through FCT-Fundação para a Ciência e Tecnologia through project UIDB/04728/2020.

Acknowledgments: We appreciate four anonymous reviewers for their insightful suggestions and constructive comments. We are grateful to the editors for their patient work on our manuscript and many thanks for all your support.

Conflicts of Interest: The authors declare no conflict of interest. 


\section{References}

Aldridge, Irene, and Steven Krawciw. 2017. Real-Time Risk: What Investors Should Know About FinTech, High-Frequency. Hoboken: Wiley Publishing.

Annicchiarico, Barbara, and Nicola Giammarioli. 2004. Fiscal Rules and Sustainability of Public Finance in an Endogenous Growth Model. ECB Working Paper No. 381. Frankfurt: European Central Bank.

Brown, Cynthia Stokes. 2012. Big History: From the Big Bang to the Present. New York: The New Press Publisher.

Dimitriu, Mihail, and Otilia Manta. 2017. Architecture of Flows and Financial Stocks-Mechanism and Transmission Channels, Flow, Transmitters and Receivers. In Proceedings of the 2017 2nd International Conference on Modelling, Simulation and Applied Mathematics (MSAM2017). Edited by Mohammad Gholami, Ram Jiwari and Kevin Weller. Advances in Intelligent Systems Research. Paris: Atlantis Press, vol. 132, pp. 219-25.

EIB. 2007. Climate Awareness Bonds. Available online: https://www.eib.org/en/investor_relations/cab/index.htm (accessed on 1 September 2019).

European Commission. 2018. EC Action Plan on Financing Sustainable Growth. Brussels: European Commission.

European Commission. 2020a. The Multiannual Financial Framework for the Period 2021-2027. Brussels: European Commission.

European Commission. 2020b. The European Green Deal Investment Plan and Just Transition Mechanism Explained. Brussels: European Commission, January 14.

Han, Yan, Xue-Feng Shao, Xin Cui, Xiao-Guang Yue, Kelvin J. Bwalya, and Otilia Manta. 2019. Assessing Investor Belief: An Analysis of Trading for Sustainable Growth of Stock Markets. Sustainability 11: 5600. [CrossRef]

He, Han, Sicheng Li, Lin Hu, Nelson Duarte, Otilia Manta, and Xiao-Guang Yue. 2019. Risk Factor Identification of Sustainable Guarantee Network Based on Logistic Regression Algorithm. Sustainability 11: 3525. [CrossRef]

Helwege, Jean, Jing-Zhi Huang, and Yuan Wang. 2014. Liquidity effects in corporate bond spreads. Journal of Banking \& Finance 45: 105-16.

Kaprauny, Julia, and Christopher Scheinsz. 2019. (In)-Credibly Green: Which Bonds Trade at a Green Bond Premium? Working Paper. Frankfurt: Goethe Universität Frankfurt.

Manta, Otilia. 2018. Microfinance: Concepts and Applications in Rural Environments. Saarbrücken: LAP Lambert Academic Publishing.

Manta, Otilia P., and M. Dimitriu. 2017. Architecture of Flows and Financial Stocks (Mechanism and Transmission Channels, Flow, Transmitters and Receivers). In 2nd International Conference on Modelling, Simulation and Applied Mathematics (MSAM2017). Publicarea în Advances in Intelligent Systems Research, Volume 132, 2nd International Conference on Modelling, Simulation and Applied Mathematics (MSAM 2017). Paris: Atlantis Press.

McWaters, R. Jesse. 2015. The Future of Financial Services: How Disruptive Innovations Are Reshaping theWay Financial Services Are Structured, Provisioned and Consumed. Geneva: World Economic Forum, p. 125.

Ministry of Economy. 2020. Integrated National Plan in the Field of Energy and Climate Change 2021-2030, Bucharest, Romania. Available online: https://ec.europa.eu/energy/sites/ener/files/documents/romania_draftnecp_en.pdf (accessed on 13 February 2020).

Ristea, Lucia, and Valeriu Franc. 2013. Methodology in Scientific Research. Bucharest: Expert Publishing House.

Sanicola, Lenny. 2017. What is fintech? Huffington Post. Available online: https://www.huffpost.com/entry/whatis-fintech_b_58a20d80e4b0cd37efcfebaa?guccounter=1\&guce_referrer=aHR0cHM6Ly93d3cuZ29vZ2xlLnJv L3VybD9zYT10JnJjdD1qJnE9JmVzcmM9cyZzb3VyY2U9d2ViJmNkPSZ2ZWQ9MmFoVUtFd2pwNmNuX 2dZX3NBaFdrc2FRSOhWZTRCSkVRRmpBQWVnUUlCaEFCJnVybD1odHRwcyUzQSUyRiUyRnd3dy5od WZmcG9zdC5jb20lMkZlbnRyeSUyRndoYXQtaXMtZmludGVjaF9iXzU4YTIwZDgwZTRiMGNkMzdlZm NmZWJhYSZ1c2c9QU92VmF3MHl3eF93YWhjcmFqVmtGWW1WanFodA\&guce_referrer_sig=AQAAACe R-ndSJ08INpiQ-1oT7KfzqB8ZfmfI2sVMkL3VLfoDPV4XQ1BtEUZPwcB1_Rb_iu93kWdd2O6GxK5_isipDVnbLs eBmP1kLQ7pCgq08UqayM2aBoJanS1e4r8n_bGuxTN6DE4qdEybW2uL3fiiaYj5tEwO1szUR0b1i1upWxmZ (accessed on 13 February 2020).

Schoenmaker, Dirk, and Willem Schramade. 2019. Principles of Sustainable Finance. Oxford: Oxford University Press. Scholten, Miroslava. 2017. Mind the trend! Enforcement of EU law has been moving to 'Brussels'. Journal of European Public Policy 24: 1348-66. [CrossRef]

Schueffel, Patrick. 2017. The concise Fintech Compedium, School of Management Fribourg, School of Management Fribourg (HEG-FR), HES-SO. Western Switzerland: University of Applied Sciences and Arts. 
World Bank. 2018. The Green Bond Market: 10 Years Later and Looking Ahead (Authors: Heike Reichelt, Head of Investor Relations and New Products, World Bank, Colleen Keenan, Senior Financial Officer, Investor Relations, World Bank). Available online: http://pubdocs.worldbank.org/en/554231525378003380/ publicationpensionfundservicegreenbonds201712-rev.pdf (accessed on 1 September 2020).

Yue, Xiao-Guang, Yong Cao, Nelson Duarte, Xue-Feng Shao, and Otilia Manta. 2019. Social and Financial Inclusion through Nonbanking Institutions: A Model for Rural Romania. Journal of Risk and Financial Management 12: 166. [CrossRef]

Zonis, Marvin. 2000. A New Decade for Business: Twenty-Four Principles of Globalization. New York: Harry Walker Agency. 